\title{
THE IMPACT OF CLINICAL PATHWAY IMPLEMENTATION ON LENGTH OF STAY AND HOSPITAL COST: A SYSTEMATIC REVIEW
}

\section{Herlin Putri Tanjung, Atik Nurwahyuni}

Faculty of Public Health, Universitas Indonesia

\begin{abstract}
Background: Clinical Pathway (CP) is a method of clinical documentation that reflects clinical practice standards for physicians, nurses, and other members of healthcare team. Clinical pathways are increasingly being used by hospitals to improve efficiency in the care of certain patient populations. This study aimed to review systematically the impact of CP implementation on length of stay and hospital cost.

Subjects and Method: A systematic review was conducted by searching published articles from 2010 to 2019 from databases including: Proquest, Scopus, and Pubmed. The keywords for this review "impact, implementation, clinical pathways, critical pathways, care pathways, integrated care pathways, hospital costs and length of stay". The dependent variables were length of stay and hospital cost. The independent variable was CP. There were 7 articles obtained after implementing the inclusion criteria.

Results: There was a significant reduction in hospital costs and length of stay after the implementation of CP. There was no significant difference between before and after the application of $\mathrm{CP}$ in aspects of complication, mortality, readmission, and clinical outcome.

Conclusion: Implementation of $\mathrm{CP}$ can significantly reduce hospital length of stay and cost without reducing the quality of health service.
\end{abstract}

Keywords: clinical pathway, length of stay, hospital cost

Correspondence:

Herlin Putri Tanjung. Faculty of Public Health, Universitas Indonesia, Depok, West Java. Email: drherlinputri@gmail.com. Mobile: 081584203086.

The $6^{\text {th }}$ International Conference on Public Health

Best Western Premier Hotel, Solo, Indonesia, October 23-24, 2019 | 303

https://doi.org/10.26911/the6thicph.04.65 